\title{
Development of Drainage and water supply systems to reduce water consumption in Residential Buildings in Egypt
}

\author{
Mahmoud Taha Abulkasem ${ }^{1}$, Sayed Marey Nagy ${ }^{2}$ \\ 1 Assistant Professor, Architecture Department, Faculty of Engineering, Badr University in Cairo, \\ email: mahmoud.taha@buc.edu.eg \\ 2 Assistant Professor, Architecture Department, Faculty of Engineering-Mattaria, Helwan \\ University,email: Sayed_Nagy@m-eng.Helwan.edu.eg
}

\begin{abstract}
The issue of water is gaining Egypt's attention in recent times, especially after the start of the Ethiopian Dam and Egypt's entry into the era of water poverty, where water is considered one of the most important natural and environmental resources. Moreover, the constant pursuit of increasing development rates, Wherever the residential building sector acquires a large proportion of water consumption between different activities. The research aims to rationalize water consumption in residential buildings by developing water supply and drainage systems responsible for distributing water within various units and spaces. Consequently, the research focuses on water treatment and the integration of water reuse techniques within residential buildings. The research studies a repeated porotype of economy housing in new cities in Egypt. The study surveyed number of users of the same levels to get the water consumption rates per unit. The research finds that water consumption can be reduced by $30.4 \%$ in residential units by modifying water supply and drainage systems design Which is reflected in the cost savings. In addition, the cost of proposed system can be returned within 2.5 years comparing to the savings cost.
\end{abstract}

Keywords:

Water Conservation, Drainage Treatment, Water Reuse, Drainage Systems, Residential Buildings, Sustainable Building.

\section{Introduction}

Water is one of the most important natural and environmental resources and essential for all development activities, especially urban development. However, Egypt has many natural water sources, such as the Nile River and a groundwater reservoir in the Eastern and Western Desert [1]. However, Egypt's per capita annual water consumption is $536 \mathrm{~m}^{3}$ per annum for 2018, lower than the global per capita average of $1,000 \mathrm{~m}^{3}$ annually. 
Egypt's per capita share is expected to decrease to $330 \mathrm{~m}^{3}$ by 2050 [2]. With Egypt exposed to many of the challenges caused by the construction of the Ethiopian Renaissance Dam and the consequent possible reduction of Egypt's water share. Water is a top priority and concern in all development sectors, and the importance of maintaining existing water resources, where the residential building sector accounts for a large proportion of water consumption among various urban activities .The residential sectors for the largest share of water consumption for urban communities and buildings, as the consumption of urban sector buildings, is more than the total tourism and industrial sectors and facilities in the rural center, where they account for 1,437 million cubic meters of water as in figure 1 [3].

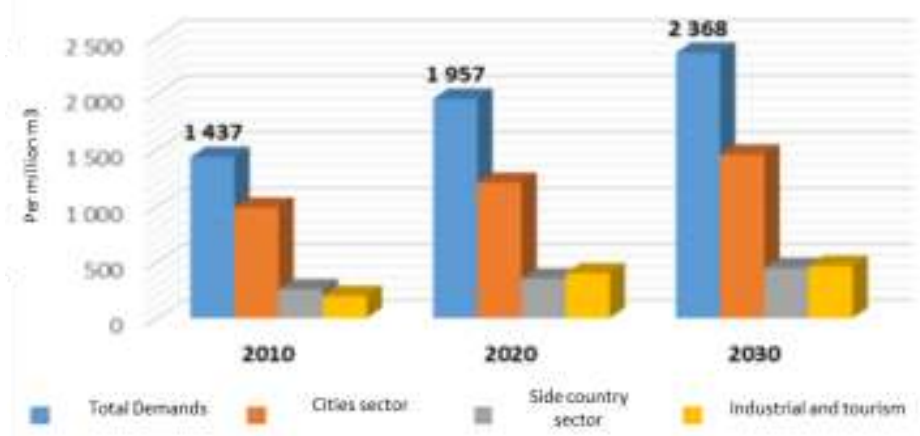

Figure 1 Development of water consumption distribution of sectors in Egypt [4]

Water consumption in units and residential complexes varies on drinking water, bathrooms, kitchens within buildings, irrigation, and site. Coordination work beyond residential complexes requires a review of the use of water inside residential buildings. The reasons for increasing consumption and a review of the design of water systems within residential complexes to reduce waste and maximize the utilization of water resources, thus achieving the objectives of water conservation, Reuse, and initial on-site treatment [5].

Water sustainability in residential buildings faces many challenges and constraints: the lack of awareness of users of the importance of water preservation and the lack of water overuse [6]. Furthermore, reducing water loss caused by low-efficiency appliances, plumping connections and sewage systems, waste of rainwater, which is a source of alternative water, and directing it to sewage systems that have difficulty in being able to discharge rainwater and surface water from streets and rooftops [7].

The problem lies in the poor efficiency of the plumbing devices, the absence of an integrated system to reduce water consumption and rainwater collection, and the inadequateness of traditional drainage and nutrition systems for the idea of reusing water in residential units and complexes. Research hypothesizes that developing water and drainage systems in residential buildings will affect water consumption and plumbing performance strategies that reduce water consumption in residential buildings.

The research explains water sustainability techniques applied in residential buildings, discusses water consumption rates per capita, compares them with discharge rates in drainage devices, and concludes the relationship between 
consumption and plumbing design requirements. Justify the traditional plumbing design to reach development mechanisms that increase network efficiency. Study models of economy housing projects in the government sectors and draw strengths and weaknesses to propose a model for developing the plumping design to reduce the water consumption in residential buildings.

\section{Water sustainability strategies in residential buildings}

Achieving sustainability in buildings requires a commitment to achieve water efficiency standards during the life cycle of the building, starting with the stage of design, implementation, operation, and maintenance of the building's life cycle, through several axes, the most important of which is reducing consumption, reducing waste, employing recycling methods, reusing, and employing alternatives to achieve the required objectives, the used strategy was highlighted as in figure 2 , which can be explained as follows $[7,8]$ :

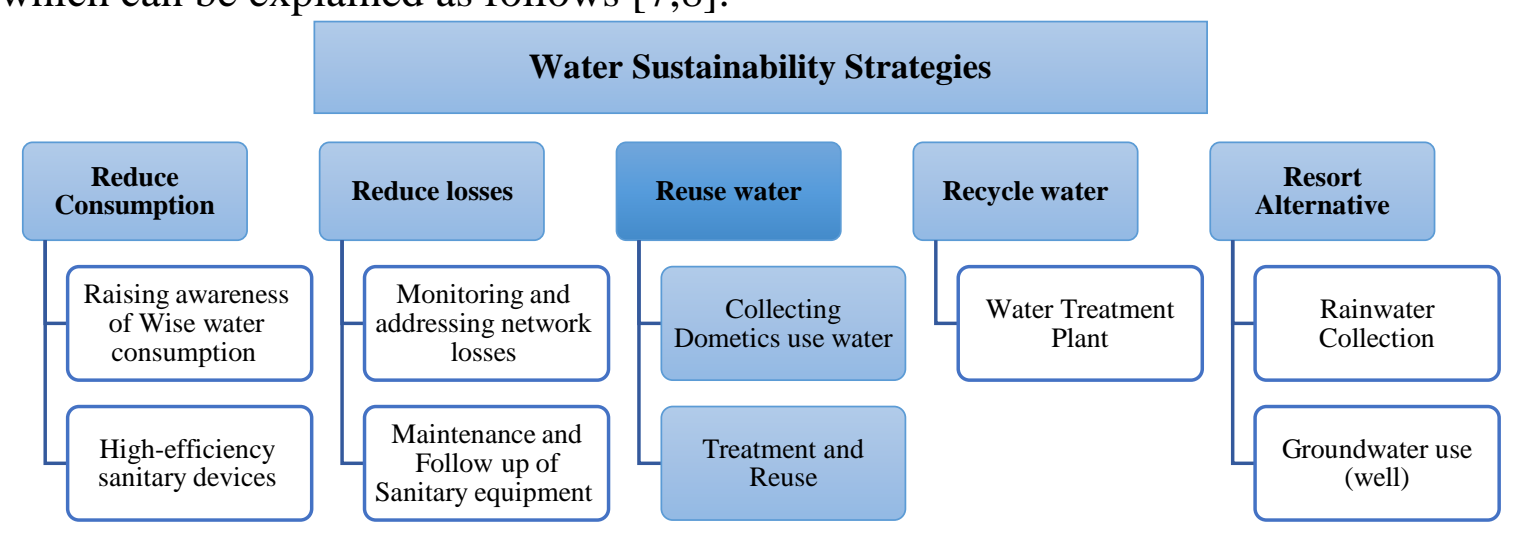

Figure 2. Water sustainability strategies, adopted [7-9]

\subsection{Reduce Water}

The concept of reducing consumption refers to reducing the amount of water consumed in buildings, which first begins with changing the culture of users, influencing the pattern of consumption within buildings, and raising awareness of the importance of water conservation as a vital source through awareness campaigns in different media [9]. Secondly, reducing the reliance on potable water for construction and construction and the site coordination elements' excellent design prioritizes plants' use from the local environment.

\subsection{Reduce Losses}

Reducing water loss involves monitoring and treating losses in buildings' health systems and devices and reducing losses. The use of innovative waterefficient appliances contributes to water conservation [10], such as touch infrared and other modern technologies as in Figure 3.

\subsection{Reuse Water}

Grey Water is defined as collecting water from showers, hand-washing basins, and automatic washing machines that can be treated and filtered in biological filters for Reuse in garden irrigation or sometimes even in package boxes [11]. And a model of the method of utilizing greywater in building as Figure 4. 


\subsection{Recycle Water}

The concept of water recycling refers to processing water collected for Reuse, such as in grey and rainwater, or the complete treatment of "Black Water" resulting from toilets, urinals, kitchen sinks, and dishwashers highly concentrated organic pollutants [12]. Integrated water treatment plants that purify, treat, and sterilize water and make it reusable can also be integrated into residential units in the toilet's ejection box, or out of buildings, in site coordination [13].

\subsection{Resort Alternatives}

Alternative water sources come from outside the public water system, which may come from, for example, rainwater, groundwater, or well water collection. Rainwater that falls on buildings can be collected and stored in water tanks for treatment and Reuse [14]. Egypt's cities, especially the northern coasts, have great rainfall chances in appropriate quantities that make them a source of access to clean water and less precipitation in Cairo and new cities. However, the chances of seasonal rains in winter and autumn remain and can be collected from rooftops and stored with ground reservoirs and purified for Reuse [3].

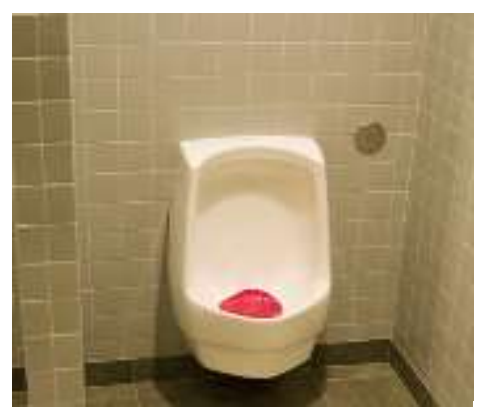

A) Low-Flow Urinal

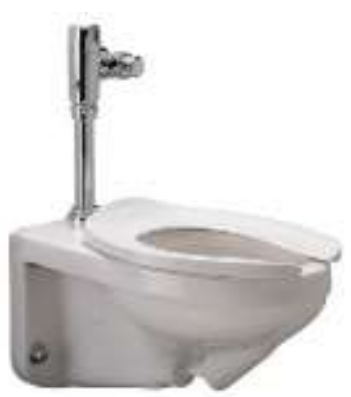

B) Dual Flush Toilet

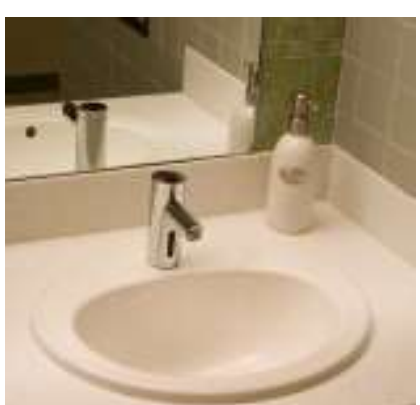

C) High-Efficiency Faucet

Figure 3. Examples of Water Efficient Sanitary equipment [15]

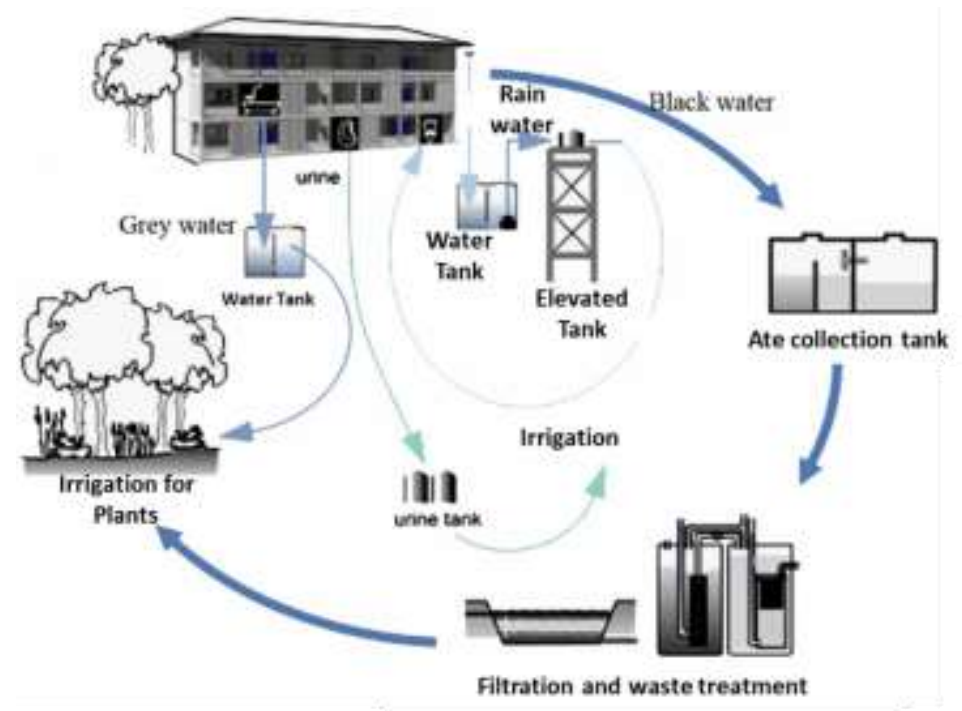

Figure 4. Water recycling and re-use methods in buildings, adopted [16] 


\section{Water supply and drainage (plumbing) systems in residential buildings}

The Egyptian code and the building regulations used in the design of drainage and feeding networks in residential buildings require a set of criteria, the most important of which are:

\subsection{Drainage Systems in Residential Buildings}

There are many drainage systems used in the design of internal drainage systems for residential buildings, each with a code for defining the strategy and its requirements, and the drainage systems that comply with Egyptian building requirements are summarized as follows, figure 5:

\section{A. One-stack System}

This system relies on the assembly of all devices used in the consumption of water and discharge on only one (ascending) column and requires the use of a ventilation stack for all single devices as follows $[17,19,20]$ :

\section{B. Tow-stacks System}

In this system, the drainage load is employed by two columns, one for drainage and the other for work with one or two columns for ventilation. It is the most common system, especially in residential complexes, in figure 5 and illustrated as follows:

○ Waste Stack (WS): Used to drain laundry tubs, kitchen sinks, floor siphons, bathroom sinks, showers, washing machines, and the like. It is usually 3 inches in diameter in residential buildings.

- Solid Stack (SS): Used to drain toilets, urinals, and the like, usually 4 inches in diameter in residential buildings. Sometimes another ventilation shaft is used to ventilate appliances on the drainage shaft in this system. It is the most common system, especially in residential buildings

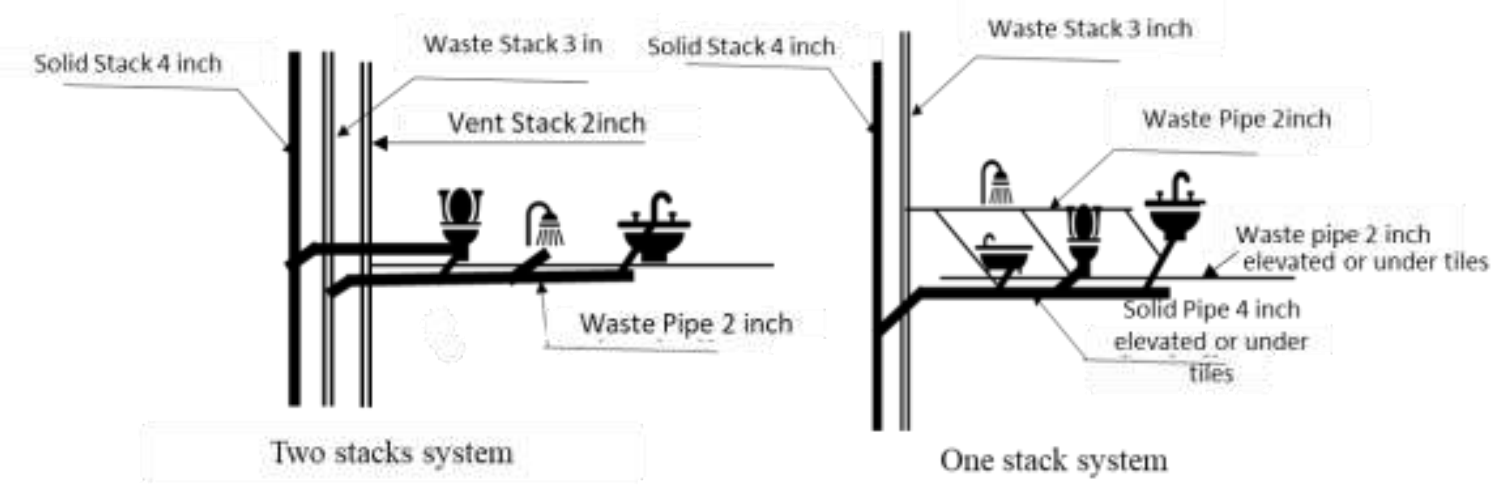

Figure 5. Common Drainage systems in Egypt, adopted [18]

\subsection{Water supply systems in residential buildings}

water supply systems provide water with appropriate pressures. They must be equipped with the proper design for water-supply pipes and the needs of the required tanks and tanks to increase water pressure in the building's internal water system to reach the required heights at the appropriate pressure [19]. 
Water supply systems vary within residential buildings according to the amount of consumption, the number of housing units, heights of buildings, and the internal network that should be safe and non-toxic materials. The choice of highly efficient materials is not affected by the quality and components of the water passing by them [20].

Table 1: Types of water supply systems used in residential buildings, adopted [18-20]

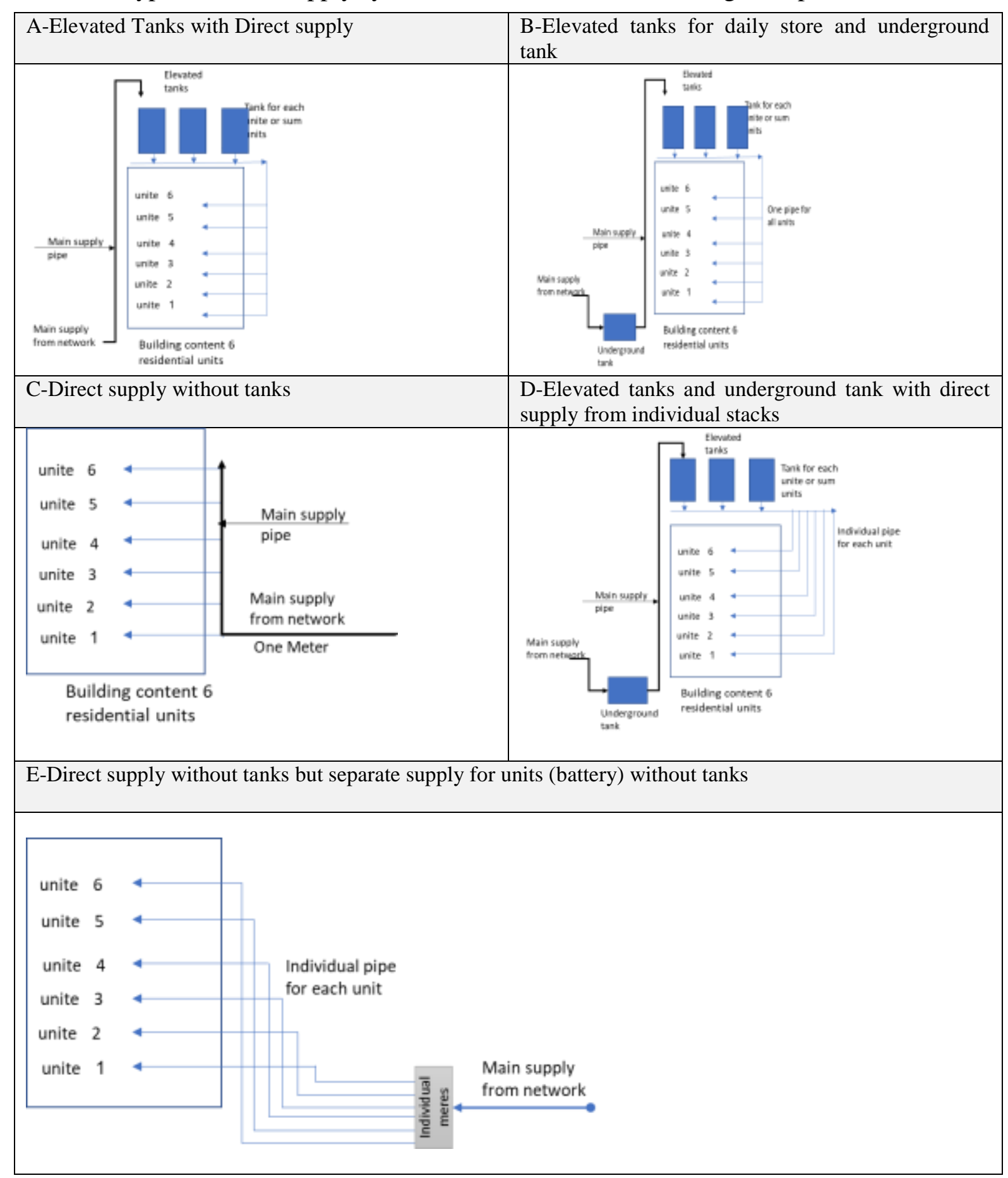




\subsection{Water consumption rate in residential buildings}

Average water consumption in residential buildings in new cities ranges from 100-400 liters/person/day [19]. While the distribution of water consumption within residential units varies depending on the family activity and the number of individuals using different water and sanitary devices. The figures and consumption from various resources rely on the culture and methodology of the analysis test. The research can divide each device's consumption or feature using water as average

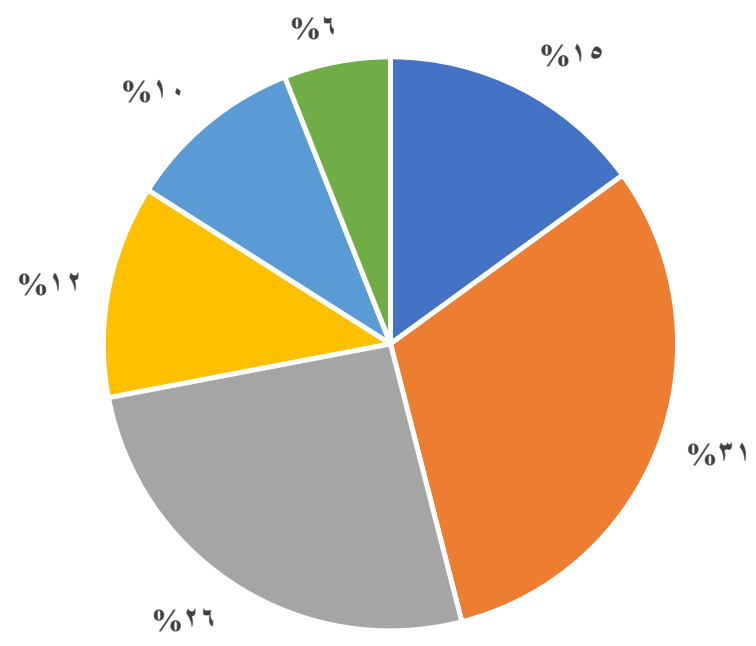

- Drinking and cooking

- Flushing WC

- Shower basin

- Loundry

- Dish washer

- External and other

Figure 6. Water consumption rates for appliances in residential units, adopted [21] [21-22].

\section{Survey of water consumption in residential buildings}

The research has an online survey for the government economy residential users, and the representative sample have some features: the apartment areas vary from 100 to $200 \mathrm{~m} 2$, with an average of $160 \mathrm{~m} 2$. Number of rooms percentage is (2 rooms 5\% - 3 rooms $78 \%$ - more than 3 rooms 17\%). number of bathrooms in apartments ( 1 bathroom 13\% - 2 bathrooms $74 \%$-more than 2 is $13 \%$ ). the number of users varies from 3 to 8 person with an average of 5 users per apartment. Having a washing machine is $100 \%$ while having a dishwasher is only $45 \%$.

Water national companies divide the value for water consumers according to the monthly consumption segments (Low consumption from 0-20 cubic meters, Average 21-30 cubic meters, High 31-40 cubic meters, and Very high over 40 cubic meters). (Source of the water company)

The survey results show the increase in the cost of monthly water consumption during the summer, and $60 \%$ of users join the very high consumption segment, whose cost exceeds 200 pounds per month and gradually decreases during the months of spring, autumn, and winter as in Figure 7. 


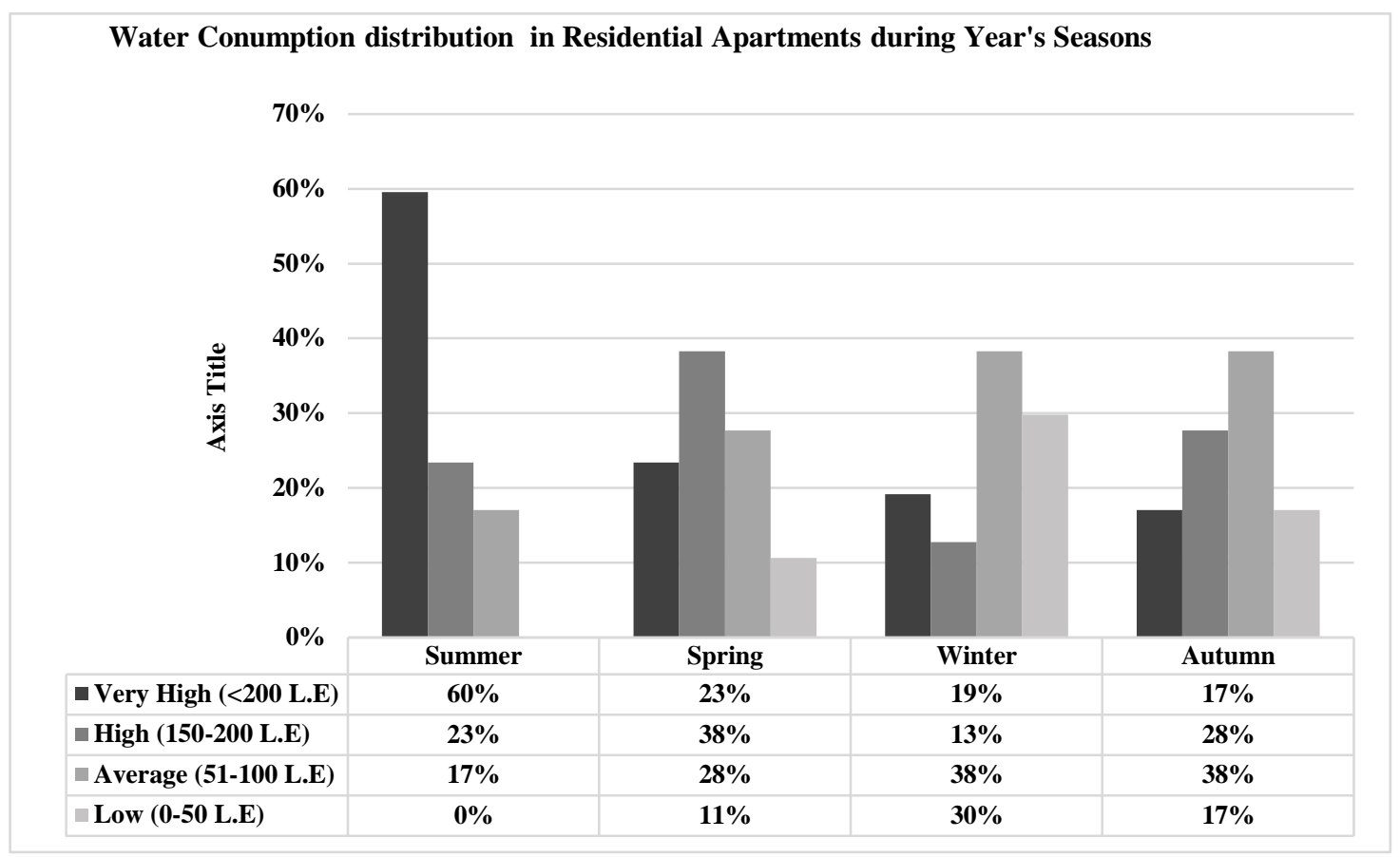

Figure 7. Water Consumption distribution in Residential Apartments during Year's Seasons The questionnaire result also shows that the very high and high section represents (a cost of more than 150 EGP per month bill), which expresses the categories of consuming water quantities higher than 30 cubic meters per month. It represents $83 \%$ of users during summer and decreases to $61 \%$ in spring, then $45 \%$ in autumn, and $32 \%$ during the winter months.

The average amounts of water consumed monthly in residential apartments were calculated on an annual basis, which shows that $30 \%$ of users consume more than 40 cubic meters per month, that $26 \%$ of users consume between $31-40 \mathrm{~m} 3 / \mathrm{M}$, while that $30 \%$ of users consume. Moreover, between $21-30 \mathrm{~m} 3 / \mathrm{M}$ and $14 \%$ of users consume less than $20 \mathrm{~m} 3 / \mathrm{M}$, as in Figure 8.

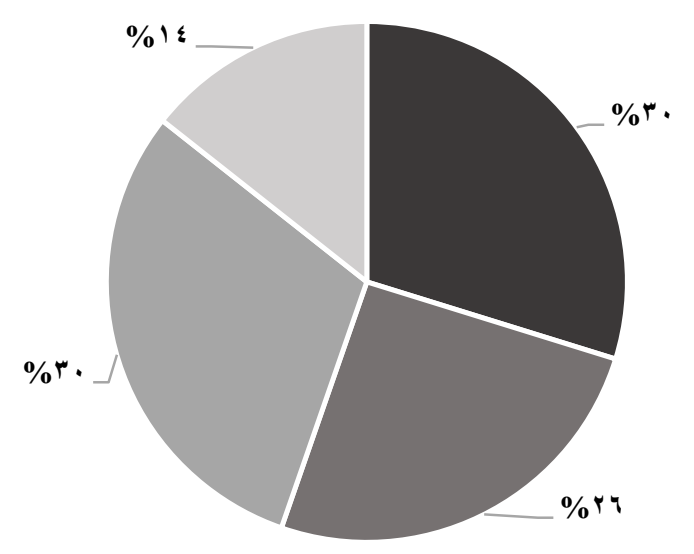

- Very High $(<40 \mathrm{~m} 3)$

- High (31-40 m3)

- Average (21-30 m3)

$\square$ Low $(0-20$ m3)

Figure 8. Distributions of residential apartments water consumption Monthly 


\section{Typical economy residential complex in Egypt (Case study)}

In line with Egypt's strategy to achieve vision 2030, the Ministry of Housing is constructing and providing thousands of housing units through two categories: Economy and Social. These housing categories are the most targeted in the new cities, so the research studies one of the typical projects in The City of Shorouk [23].

The building code refers to the average per capita consumption of 100 to 400 , which is a varying percentage between the low level of housing to luxury housing, so the research conducted a random questionnaire addressed to residents or users of the Dar Misr project to determine the housing level and average consumption of water.

Table 2. Sample of Government housing project

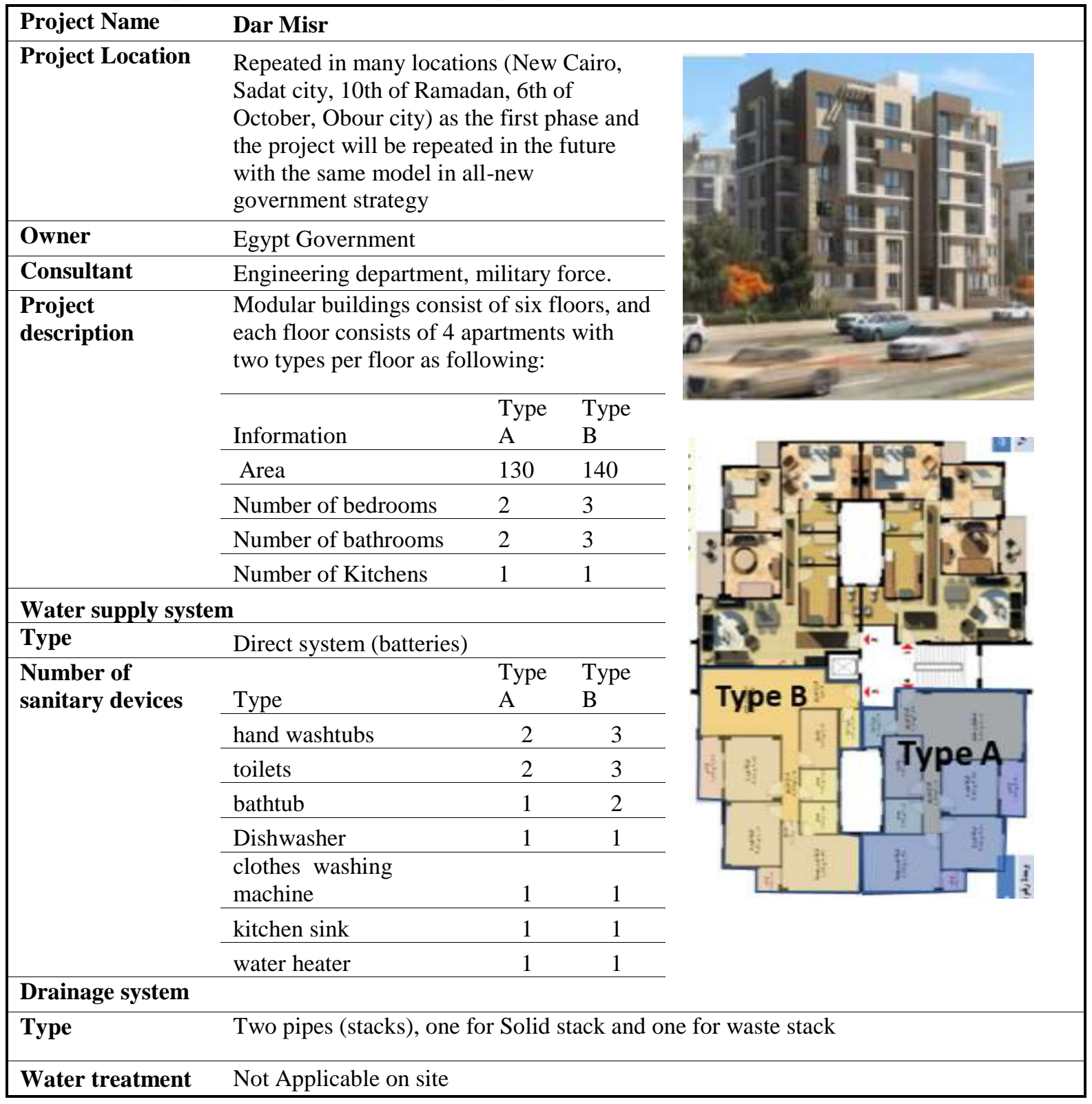




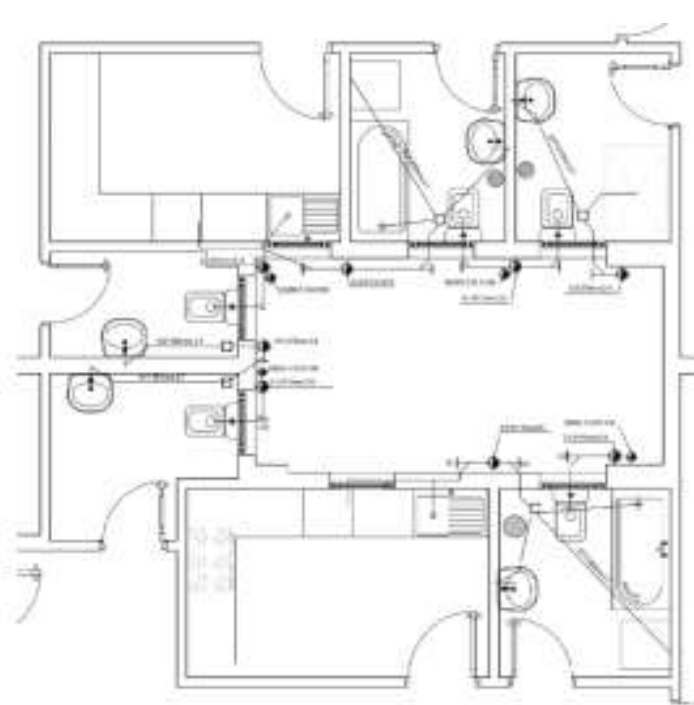

a. Plumping system in Dar-Misr

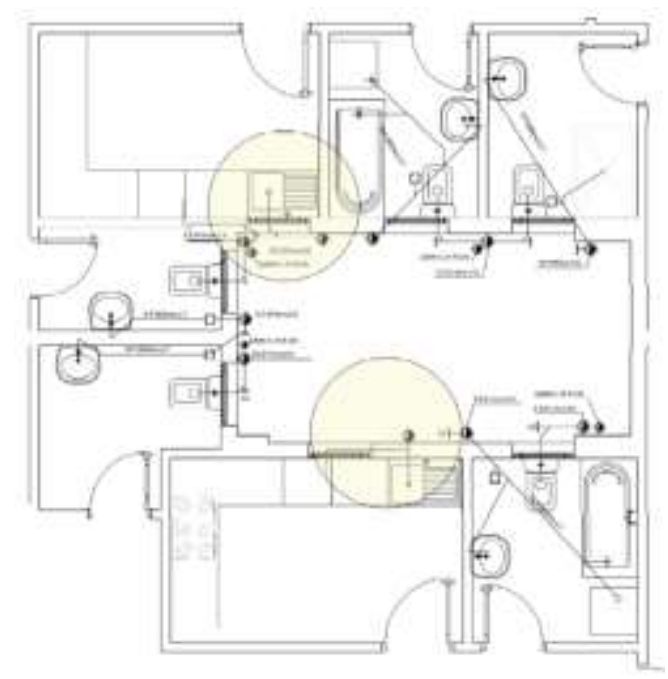

b. Proposed Plumping system in Dar-Misr

Figure 9. Distributions of residential apartments water consumption Monthly

\section{1 analysis of plumbing system}

The used drainage system is the traditional way contents of two pipes with ventilation stack, the typical floors have been collected in the ground floor level and separately of the ground floor drainage in figure 9a as follow:

a) The ground floor drainage system: It is assembled directly to inspection rooms where both the solid stack and the waste stack collected from different drainage types have been observed. The composition of the collected water contains organic elements, acids, and chemical elements such as soap.

b) The drainage system of typical floors: The drainage exits are assembled according to the established procedure. As noted, all the wastewater from the bathtub, washing basin hands, and ground siphon to the drainage pipe. The wastewater is separated from the discharge of the output from the toilet.

c) Water supply system: The suppling system is related to table 1 as direct supply without tanks (battery system).

\section{Proposed model of a plumbing system}

The case study analysis shows that residential units designed for an average of five users, and according to Egypt's codes, every person consumes from 250 to 300 liter daily. Besides, the amount of wastewater without oils is $38 \%$ of water consumed, nearly equal to the volume required to fill toilet flush appliances in residential units [24]. The proposed modification is to separate the drainage stack for the greywater without kitchen devices besides the existing two pipes system. Describe as in figure 9b, 10 . 


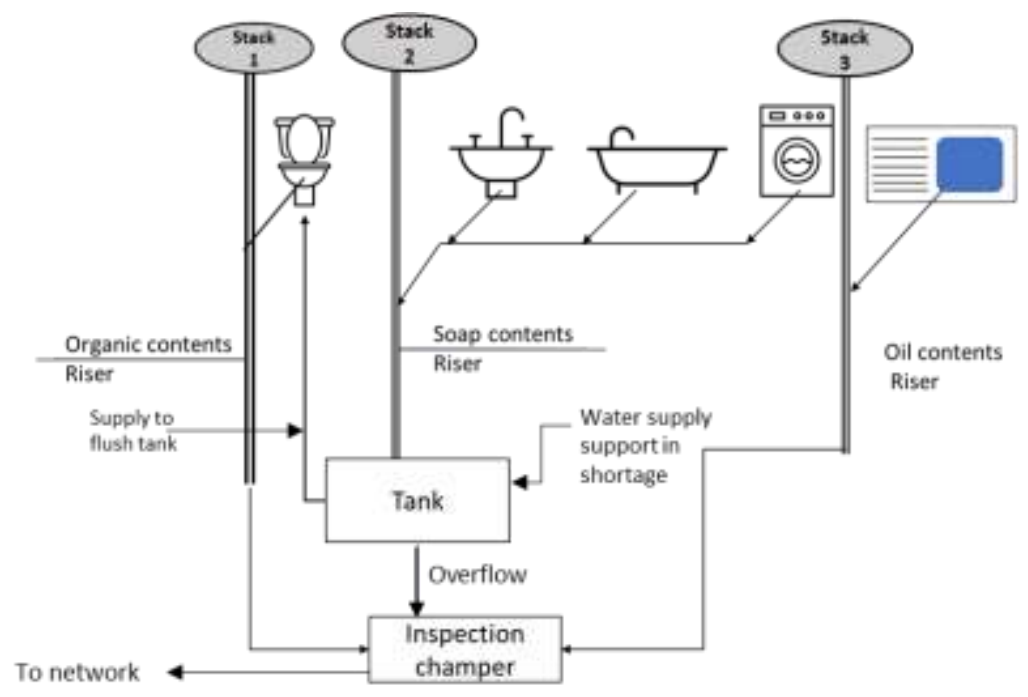

Figure 10. Proposed modification of Plumping system for Residential building

The proposed system decreases the total amount of water consumption in residential units where it collects greywater in an underground tank and reuses it again in toilets' flush tanks. According to the average amount of water consumed in residentials' appliances, the Consumption calculation in table 3 shows that the average saving percentage is $30.4 \%$.

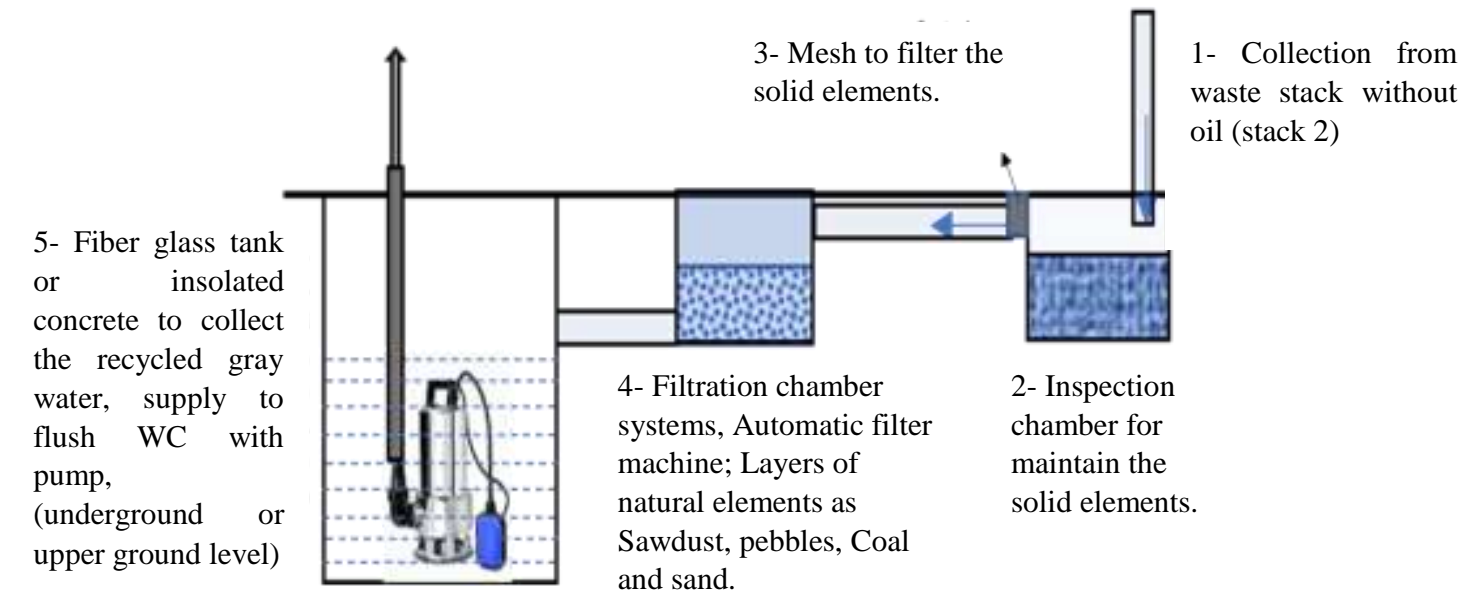

Figure 11. Diagram of proposed Greywater system for Residential building

The proposed systems' initial cost contains the modification of drainage and water supply system, the price of underground tanks, and finally, constructing and operating it. The proposed method has a high value of initial cost than the traditional system. It decreases the average monthly bills excluding the proposed system's initial cost, explained in table 4. And the calculation of cost analysis shown in table 5 . 
Table 3 Calculation of proposed system water consumption

Consumption study of one model of water where (average per capita consumption per day for residential buildings $)=$ average number of beds in Egypt is 5 individuals $=5 x 250=1250 \mathrm{~L}$ per day

\begin{tabular}{|c|c|c|c|c|c|c|c|c|c|}
\hline Device & 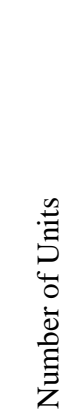 & 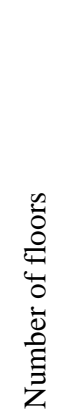 & 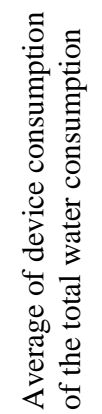 & 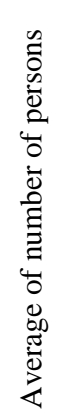 & 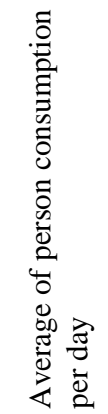 & 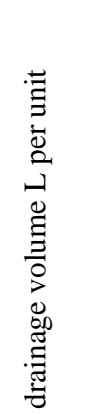 & 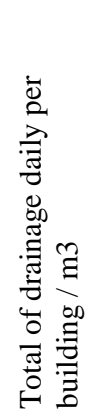 & 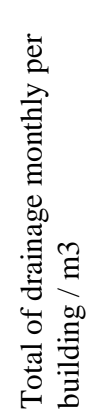 & \\
\hline *WF-WC flushing & 4 & 6 & $31 \%$ & 5 & 250 & 387.5 & 9.3 & 279 & \\
\hline EO-External and others & 4 & 6 & $6 \%$ & 5 & 250 & 75 & 1.8 & 54 & \\
\hline WS-Washing and Shower & 4 & 6 & $26 \%$ & 5 & 250 & 325 & 7.8 & 234 & \\
\hline L-Laundry & 4 & 6 & $12 \%$ & 5 & 250 & 150 & 3.6 & 108 & \\
\hline D-Drinking \& cooking & 4 & 6 & $15 \%$ & 5 & 250 & 187.5 & 4.5 & 135 & \\
\hline DW-Dishwashing machine & 4 & 6 & $10 \%$ & 5 & 250 & 125 & 3.0 & 90 & \\
\hline \multicolumn{9}{|c|}{ Total monthly consumption of building $/ \mathrm{m}^{3}$ ( Sum. Of all above devices) } & 900 \\
\hline \multicolumn{9}{|c|}{ Total monthly consumption per Apartment $/ \mathrm{m}^{3}$ ( Sum. Of all above devices) } & 37.5 \\
\hline \multicolumn{9}{|c|}{ Total for Greywater $/ \mathrm{m}^{3}(\boldsymbol{G} \boldsymbol{W}=W S+D)$} & 342 \\
\hline \multicolumn{9}{|c|}{ Total Monthly drainage per building (with fat and oil contents) $/ \mathrm{m}^{3}\left(\boldsymbol{G} \boldsymbol{W}_{f}=D+D W\right)$} & 225 \\
\hline \multicolumn{9}{|c|}{ Proposed of Reuse water $\mathrm{m}^{3} /$ unit/month } & 14.25 \\
\hline \multicolumn{9}{|c|}{ The efficiency of reuse system $=80 \%\left(\mathrm{~m}^{3}\right),[3]$} & 11.4 \\
\hline \multicolumn{9}{|c|}{$* *$ Percentage of reduction in water consumption } & $30.4 \%$ \\
\hline
\end{tabular}

$* \mathrm{WF}=$ no. units $*$ no. floors $*$ percentage of device consumption* No. of persons $*$ avg. of person consumption $* 30$ days (Equation repeated for all devices)

**Percentage of reduction in water consumption $=$ Total monthly consumption per Apartment $/$ The Volume of reuse system

Table 4 Cost calculation of proposed greywater system

\begin{tabular}{|c|c|c|c|}
\hline No. & Item & $\begin{array}{l}\text { Estimated Construction } \\
\text { cost per building /EP }\end{array}$ & $\begin{array}{l}\text { Cost of proposed system per } \\
\text { apartment / EP }\end{array}$ \\
\hline 1 & Concrete tank & 10000 & \\
\hline 2 & PVC drainage pipes & 30000 & \\
\hline 3 & PPR water supply pipes & 36000 & \\
\hline 4 & Pump & 5000 & \\
\hline \multicolumn{2}{|c|}{ *CGW- Total cost of greywater system } & 81000 & 3375 \\
\hline
\end{tabular}

* Cost of greywater system equal sum. of items from 1 to 4, according to March 2021 prices in Egypt. 
Table 5 Cost Reduction in water Consumption

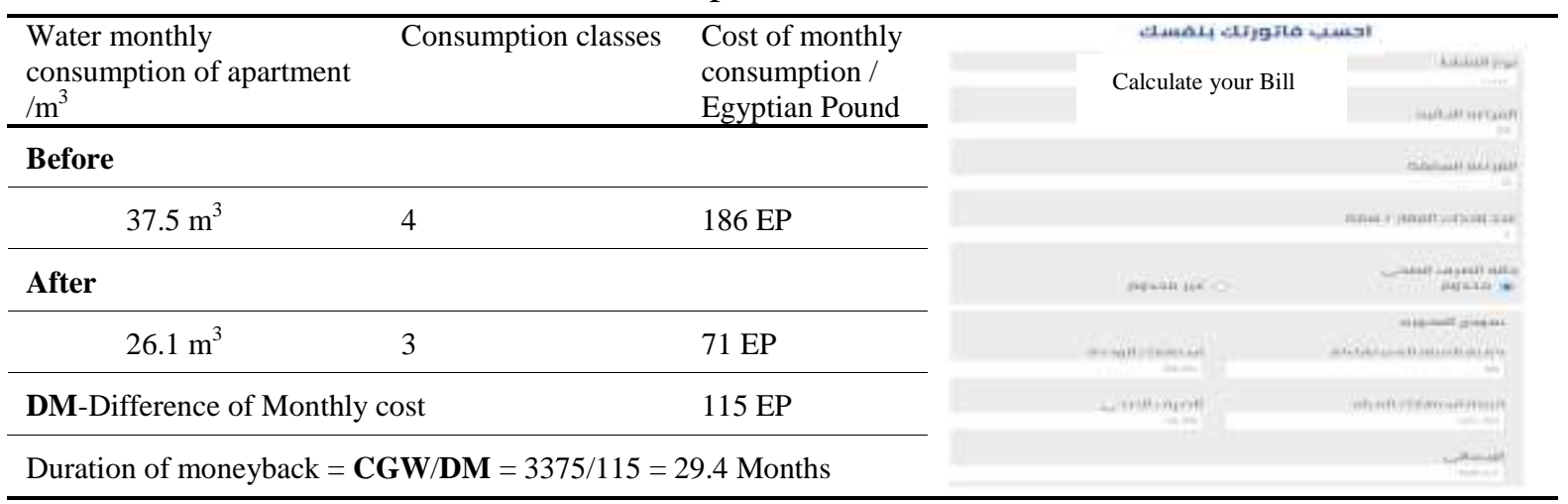

* Price of water for residential use from HCWW water company online calculator in March 2021, [25]

\section{Conclusion}

A unified plumping system is used for most of the residential buildings without developing the component and design of the drainage system and water supply that to be matching with the new project aims and sustainability strategies. To demonstrate that the research assessed one of the massing productivities projects as Dar Misr. The research found that the drainage system uses two pipes to systems collected in one way to the network without consideration of the onsite reuse system,

The research dependent on calculating the consumption rate of plumbing devices to validate those quantities of greywater without oils and fats are equal to the required volume of flush tanks. the contents of greywater affect filtration cost and process. The proposed system is to add a stand-alone stack and water supply flash tank stack to improve the greywater performance and filtration process.

the proposed system has direct benefits for users to reduce the average percentage of water consumption bills, decreasing the average amount of water consumption percentage by $30.4 \%$. the initial cost can be returned in less than 3 years.

\section{References}

1. El Tahlawi, M. R., A. A. Farrag, and S. S. Ahmed. "Groundwater of Egypt: "an environmental overview"." Environmental Geology 55.3 (2008): 639-652.

2. MWRI, Ministry of Water Resources and Irrigation, 2020, available at https://www.mwri.gov.eg/water, accessed (24/12/2020).

3. Ibrahim, Ahmed H. "Optimizing virtual water as irrigation water management strategy in Egypt." IOSR Journal of Mechanical and Civil Engineering 11.6 (2014): 41-51.

4. FAO, "Food and Agriculture Organization", available at http://www.fao.org/home/en/, accessed 1/11/202.

5. Chance, T., "Towards sustainable residential communities; the Beddington Zero Energy Development (BedZED) and beyond", Environment and Urbanization, 21(2), 2009, P. 527-544. 
6. EL-Nwsany, R. I., Maarouf, I., \& Abd el-Aal, W. (2019). Water management as a vital factor for a sustainable school. Alexandria Engineering Journal, 58(1), 303-313. https://doi.org/10.1016/j.aej.2018.12.012.

7. Pimentel-Rodrigues, C., \& Siva-Afonso, A. (2019). Reuse of resources in the use phase of buildings. Solutions for water. IOP Conference Series: Earth and Environmental Science, 225, 012050. doi:10.1088/1755-1315/225/1/012050.

8. Silva-Afonso A 2019 Building rainwater harvesting systems. Doubts and certainties Proc. CIB W062 2009 - 35th International Symposium of Water Supply and Drainage for Buildings (Dusseldorf: CIB) pp 238-246.

9. Yudelson, Jerry, "Marketing Green Building Services :Strategies for Success", Routledge, 2008, P. 267-268.

10. Honorable Rudolph W. Giuliani \& others, "High performance building guidelines", City of New York, Department of Design and Construction, April 1999.

11. Schuetze, Thorsten, and Vicente Santiago-Fandiño, "Quantitative Assessment of Water Use Efficiency in Urban and Domestic Buildings", Water 5, no. 3, 2013, p. 1172-93. doi:10.3390/w5031172.

12. Fountoulakis, M.S., N. Markakis, I. Petousi, and T. Manios, "Single House On-site Grey Water Treatment Using a Submerged Membrane Bioreactor for Toilet Flushing", Science of the Total Environment 551-552 ,2016, p. 706-11, doi:10.1016/j.scitotenv.2016.02.057.

13. Sassi, Paola, "Strategies for sustainable architecture", Taylor \& Francis, 2006, P.277.

14. Kloss, Christopher, "Managing Wet Weather with Green Infrastructure: Rainwater Harvesting Policies: US EPA", 2008. available at: https://nepis.epa.gov/Exe/ZyPDF.cgi/P1005FN2.PDF?Dockey=P1005FN2.PDF. accessed (1/11/2020).

15. WBDG, "Whole Building Design guide", available at: http://www.wbdg.org/ design/sustainable.php, Accessed (1/11/2020).

16. Building Ecology, available at: https://www.buildingecology.com/, Accessed $(1 / 11 / 2019)$.

17. HBRC, "Egyptian Code for Design and Implementation Requirements for the Engineering of Sanitary Structures of Buildings". Volume 1, Centre for Housing and Construction Research, Cairo, 2009.

18. Roger Greeno, Fred Hall. Building Services Handbook. Elsevier. 4th Edition. 2007, p.311-316.

19. HBRC, "Egyptian Code for Design and Implementation Requirements for the Engineering of Sanitary Structures of Buildings". Code No.301, Volume 1, Centre for Housing and Construction Research, Cairo, 2019.

20. HBRC, "Egyptian Code for Design and Implementation Requirements for the Engineering of Sanitary Structures of Buildings". Code No.301, Volume 2, Centre for Housing and Construction Research, Cairo, 2019.

21. Sisolak, Joel, and Kate Spataro. 2011. Toward Net Zero Water: Best Management Practices for Decentralized Sourcing and Treatment. Cascadia Green Building Council. Available at http://living-future.org/ilfi/ideas-action/research/water/towardnet-zero-water, accessed (1/11/2020).

22. Ibrahim, M., A. Bakr, and A. Abdel-Aziz. "Water Management in Existing Residential Building in Egypt (Gray-Water System)." International Journal of Scientific \& Engineering Research 3, no. 8 (2012). 
23. MHUC, "Ministry of Housing, utilities and urban communities: Housing Projects", available at http://www.mhuc.gov.eg/, accessed (1/1/2020).

24. Dixon, A, D Butler, and A Fewkes, "Water Saving Potential of Domestic Water Reuse Systems Using Greywater and Rainwater in Combination", Water Science and Technology 39, no. 5 (1999): 25-32. doi:10.1016/s0273-1223(99)00083-9.

25. HCWW, "Holding company for water and wastewater", 2021, available at: https://www.hcww.com.eg/bill-calc/, accessed (1/3/2021). 